\title{
Prognostic Nutritional Index as a Predictor of Postoperative Outcome in Patients Aged 85 Years or Older After Colorectal Cancer Surgery
}

\author{
Atsushi Tsuruta $^{1} \cdot$ Yusaku Watanabe $^{1} \cdot$ Shumei Mineta $^{1} \cdot$ Hiroaki Tanioka $^{2} \cdot$ Takeshi Nagasaka $^{2} \cdot$ Yoshinori Fujiwara $^{1}$. \\ Tomio Ueno ${ }^{1}$
}

Received: 31 October 2019 / Accepted: 26 March 2020 / Published online: 18 April 2020

(C) The Author(s) 2020

\begin{abstract}
The preoperative prognostic nutritional index (PNI) calculated based on the serum albumin concentration and peripheral blood lymphocyte count has been reported to correlate with the prognosis in patients undergoing cancer surgery. However, in case of very old patients over 85 years old, the value of preoperative PNI in colorectal cancer has not been studied in any detail. The aim of this study was to assess the PNI as a predictor of postoperative outcome in elderly patients over 85 years old with colorectal cancer. We performed a retrospective review in forty-five patients over 85 years old who underwent colorectal tumor resection at our hospital from April 2013 to March 2018. The correlations between preoperative PNI and postoperative complications were examined. The incidence rate of postoperative complications was $31.1 \%$ (14/45). All of cases with postoperative complications were improved conservatively. The median preoperative PNI was 43.20 (range 24.05-57.05) in the validation study. According to the receiver operating characteristic (ROC) curve, cutoff value of PNI was set at 45.0 in the validation study. An univariate analysis demonstrated that PNI $(p=0.0006)$, operation style (elective/emergency) $(p=0.03)$, operation approach (open/laparoscopy) $(p=0.03)$, and $\mathrm{T}$ factor $(p=0.04)$. A multivariate analysis showed that PNI was independent predictive factor of postoperative complications. Moreover 3-year overall survival rates of patients in the PNI $\geqq 45$ and PNI $<45$ were $100 \%$ and $63.8 \%$, respectively $(p=0.009)$. This study suggested that PNI is a pivotal independent predictor of the postoperative outcome among elderly patients over 85 years old after colorectal cancer surgery.
\end{abstract}

Keywords Prognostic nutritional index $\cdot$ Colorectal cancer $\cdot$ Elderly patient $\cdot$ Eighty-five years old

\section{Introduction}

Incidence of colorectal cancer (CRC) has increased in recent years; CRC is the third most common cause of cancer-related death worldwide [1]. Despite improved treatments, CRC recurrences arise at a steady rate. Long-term survival and local recurrence in CRC patients are affected by postoperative complications (PCs) [2-5]. For any patient, PCs can affect quality of life and activities of daily living, but they are an especially heavy burden for elderly patients who are already suffering the stress of surgery and hospitalization. Therefore,

Atsushi Tsuruta

atsuatsu@apost.plala.or.jp

1 Department of Digestive Surgery, Kawasaki Medical School, Matsushima 577, Kurashiki, Okayama 701-0192, Japan

2 Department of Medical Oncology, Kawasaki Medical School, Matsushima 577, Kurashiki, Okayama 701-0192, Japan identifying predictors for PCs from preoperative data should help manage elderly patients.

Onodera's prognostic nutritional index (PNI) is calculated from serum albumin concentration and peripheral blood lymphocyte (PBL) count. It indicates the patient's nutritional and immunological status, and is used to predict risk of several kinds of complications after surgery [6,7]. Moreover, it has been proposed to be causally related to overall survival (OS) in some cancers [8-12].

However, we have found few reports of the relationship between preoperative PNI and PCs in very elderly $(\geq 85$ years old) patients with CRC. Therefore, this study assessed PNI as a predictor of postoperative short- and long-term outcomes in patients aged $\geq 85$ years old with CRC.

\section{Patients and Methods}

Between April 2013 and March 2018, 504 consecutive patients with primary CRC underwent radical surgical procedures at 
the Department of Digestive Surgery, Kawasaki Medical School. Among them, 45 patients who were at least 85 years old at the times of their surgeries were retrospectively evaluated in this study, using those patients' medical records, which included information on patients, their tumors, surgeries, and prognoses. Patients who underwent palliative surgery, had hematologic disease or immunologic disease, suffered from small or large bowel obstruction, or were treated with preoperative chemotherapy were excluded.

All preoperative data included height and weight measurements, and blood samples that were collected within 14 days before operation. Onodera's PNI was calculated as $(10 \times \mathrm{se}-$ rum albumin as $\mathrm{g} / \mathrm{dl})+\left(0.005 \times\right.$ PBL per $\left.\mathrm{mm}^{3}\right)$ in accordance with the well-known formula [6], and was measured within 7 days before surgery.

We defined PCs as having occurred within 30 days after surgery. They were graded by the widely used Clavien-Dindo system for classifying surgery-related adverse events (grade I: deviations from normal post-operative course that do not require surgical, endoscopic or radiological intervention; grade II: PCs requiring drug treatments other than those allowed for grade I PCs; grade III: PCs requiring surgical, endoscopic or radiological intervention; grade IV: life-threatening PCs, including central nervous system PCs; grade V: death) [13].

\section{Statistical Analysis}

Statistical analyses were performed with JMP ver. 14.0 (SAS Institute Inc., Cary, NC, USA). Data are presented as means or median values and standard deviations. Continuous variables were analyzed by Student's $t$ test and categorical variables were analyzed by the $\chi^{2}$ test. The PNI cutoff value was established by a receiver operating characteristic (ROC) curve. Survival analysis was performed using the Cox proportional hazard model. Multivariate analysis for PC incidence was performed with logistic analysis. Statistical significance was determined by $p$ values of less than 0.05 .

\section{Results}

\section{Patient Characteristics and Operative Details}

Patient characteristics are summarized in Table 1. This study included 45 eligible patients aged $\geq 85$ years old ( 21 men and 24 women). Their median age was $88.0 \pm 3.4$ years old (range 85-99 years). Of the 45 surgeries, 10 (22.2\%) were urgent. Nine patients $(20.0 \%)$ had class 3 American Society of Anesthesiologists Physical Status (ASA-PS) which quantifies surgical risk. Cardiovascular disease was the most common underlying disease. The patients collectively had 29 rightcolon tumors and 10 left-colon tumors. Their median PNI was 42.135 (range 24.05-57.05). The ROC curve for PNI
Table 1 Patient characteristics $(n=45)$

\begin{tabular}{|c|c|c|}
\hline \multirow[t]{2}{*}{ Gender } & Male & 21 \\
\hline & Female & 24 \\
\hline Age & & $88.0 \pm 3.4(85-99)$ \\
\hline Body mass index (BMI) & & $20.1 \pm 3.0$ \\
\hline Preoperative ASA/PS & $1 / 2 / 3$ & $10 / 26 / 9$ \\
\hline PNI & & $42.135(24.05-57.05)$ \\
\hline \multirow[t]{2}{*}{ Operation } & Elective & 35 \\
\hline & Urgent & 10 \\
\hline \multirow{6}{*}{$\begin{array}{l}\text { Underlying diseases } \\
\text { (there is some } \\
\text { overlapping) }\end{array}$} & Cardiovascular & 33 \\
\hline & Endocrine & 7 \\
\hline & Respiratory & 4 \\
\hline & Urologic & 4 \\
\hline & Cranial nerve & 3 \\
\hline & Rheumatic & 2 \\
\hline Tumor localization & $\begin{array}{l}\text { Right colon }(\mathrm{C} / \mathrm{A} / \mathrm{T}) \\
\text { Left colon }(\mathrm{D} / \mathrm{S}) \\
\text { Rectum }\end{array}$ & $\begin{array}{l}10 / 11 / 8 \\
4 / 6 \\
6\end{array}$ \\
\hline Approach & Open/Laparoscopic & $18 / 27$ \\
\hline Lymph node dissection & D1/D2/D3 & $5 / 10 / 30$ \\
\hline $\begin{array}{l}\text { Histological tumor type } \\
\text { (there is some } \\
\text { overlapping) }\end{array}$ & $\begin{array}{l}\text { Pap } \\
\text { Tub1 } \\
\text { Tub2 } \\
\text { Por } \\
\text { Sig } \\
\text { Muc } \\
\text { Goblet cell carcinoid }\end{array}$ & $\begin{array}{l}1 \\
32 \\
34 \\
8 \\
1 \\
11 \\
1\end{array}$ \\
\hline
\end{tabular}

indicated that the optimal cutoff value to predict PCs was 45 (area under the curve 0.72 , moderate accuracy). Patients were divided into the PNI-H group (PNI $\geq 45)$ and PNI-L group $(\mathrm{PNI}<45)$.

\section{Postoperative Complications}

Some PCs overlapped (Table 2). The most common were pneumonia and paralytic ileus ( $n=4$ for both), followed by surgical site infections $(n=3)$, intra-abdominal abscess $(n=$ $1)$, urinary tract infection $(n=1)$, melena $(n=1)$, sepsis $(n=$ $1)$, and acute heart failure $(n=1)$. Incidence of PCs was $31.1 \%$ (14/45). No patients experienced hospital death. All complications were treated with conservative therapies.

\section{Preoperative Factors Affecting Postoperative Outcome}

Table 3 shows patients' clinical laboratory and pathological characteristics by high or low PNI. Physical status of PNI-L patients was much poorer than that of PNI-H patients. Lymph node dissection, tumor burden, ASA-PS, and operation methods were significantly associated with PNI. Incidences of PCs were 5.3\% for PNI-H patients and 50.0\% for PNI-L 
Table 2 Postoperative complications

\begin{tabular}{lllll}
\hline & $n(\%)$ & \multicolumn{2}{l}{ Clavien-Dindo Grade $(n)$} \\
\cline { 3 - 5 } & & I & II & $\geq$ III \\
\hline Pneumonia & $4(8.9)$ & 4 & \\
Paralytic ileus & $4(8.9)$ & 4 & \\
Surgical site infection & $3(6.7)$ & 3 & & \\
Intra-abdominal abcess & $1(2.2)$ & & 1 & \\
Urinary tract infection & $1(2.2)$ & 1 & 1 \\
Melena & $1(2.2)$ & 1 & 1 & \\
Sepsis & $1(2.2)$ & $1(2.2)$ &
\end{tabular}

patients $(P=0.0006)$. Mean postoperative hospital stays were 15.3 days for PNI-H patients, compared with 25.5 days for PNI-L patients $(p=0.004)$.

In univariate analysis, age, PNI, and tumor location were associated with PCs. In multivariate analysis, only PNI was independently associated with PCs (odds ratio 18.74: 95\% confidence index 1.18-298.04; $p=0.038$; Table 4).

Overall survival was evaluated (Fig. 1). Three-year OS rates were PNI-H 100\% and PNI-L 63.8\%. There was significant difference between the two groups $(p=0.009)$.

\section{Discussion}

The use of a prognostic nutritional index in gastrointestinal surgery was first described by Buzby et al. in 1980 [14], who calculated their index by four factors: serum albumin, triceps skinfold, serum transferrin, and cutaneous delayed hypersensitivity reactivity grade. Although their index was potentially useful, this method was somewhat laborious for practical use. Four years later, Onodera et al. designed a more convenient PNI, based on serum albumin concentration and PBL count, which is more widely used, in Japan and elsewhere. We selected it to evaluate patients' nutritional status.

The relationship between PNI and short- or long-term prognosis in CRC patients has been the subject of some reports. We found low PNI (i.e., lower than cut-offs of 45 to 50) was an independent predictor of poor survival in four retrospective studies [11, 15-17]. PNI was significant predictor of PCs in patients with CRC who underwent primary tumor resection [15]. Yano et al. also showed that preoperative PNI was a predictor of PCs in laparoscopic colorectal surgery [18].

Several retrospective studies have indicated a cause-andeffect relationship between preoperative PNI and PCs among elderly persons with CRC. Tei et al. described a significant relationship between PNI and PCs in patients older than 71 years who underwent open colorectal surgery [19] and
Table 3 Patients' clinical laboratory and pathological characteristics by high or low PNI

\begin{tabular}{|c|c|c|c|}
\hline \multirow[b]{2}{*}{ Variable } & \multicolumn{2}{|l|}{ PNI } & \multirow[b]{2}{*}{$p$ value } \\
\hline & $\mathrm{H}(\geq 45)(n=19)$ & $\begin{array}{l}\mathrm{L}(<45) \\
(n=26)\end{array}$ & \\
\hline Gender & & & 0.936 \\
\hline Male & 9 & 12 & \\
\hline Female & 10 & 14 & \\
\hline Age (median) & 87.3 & 88.5 & 0.103 \\
\hline BMI & 20.8 & 19.7 & 0.887 \\
\hline ASA-PS & & & 0.001 \\
\hline 1 & 7 & 3 & \\
\hline 2 & 12 & 14 & \\
\hline 3 & 0 & 9 & \\
\hline Tumor location & & & 0.298 \\
\hline Right colon & 10 & 19 & \\
\hline Left colon & 5 & 5 & \\
\hline Rectum & 4 & 2 & \\
\hline Operation time (median) (min) & 227.9 & 220.8 & 0.593 \\
\hline Bleeding (mean) $(\mathrm{ml})$ & 5 & 5 & 0.066 \\
\hline Approach (open/laparoscopic) & & & 0.105 \\
\hline Open & 5 & 13 & \\
\hline Laparoscopic & 14 & 13 & \\
\hline Lymph node dissection & & & 0.022 \\
\hline D1 & 0 & 5 & \\
\hline D2 & 3 & 7 & \\
\hline D3 & 16 & 14 & \\
\hline $\begin{array}{l}\text { Tumor burden (longitudinal } \times \\
\text { transverse diameter: } \mathrm{mm}^{2} \text { ) }\end{array}$ & 11.6 & 22.0 & 0.012 \\
\hline $\mathrm{T}$ factor & & & 0.070 \\
\hline is & 0 & 1 & \\
\hline 1 & 2 & 0 & \\
\hline 2 & 5 & 2 & \\
\hline 3 & 9 & 20 & \\
\hline 4 & 3 & 3 & \\
\hline $\mathrm{N}$ factor & & & 0.270 \\
\hline 0 & 11 & 16 & \\
\hline 1 & 7 & 7 & \\
\hline 2 & 1 & 2 & \\
\hline 3 & 0 & 1 & \\
\hline Stage & & & 0.098 \\
\hline 0 & 0 & 1 & \\
\hline 1 & 6 & 2 & \\
\hline 2 & 4 & 12 & \\
\hline 3 & 9 & 9 & \\
\hline 4 & 0 & 2 & \\
\hline Operation & & & 0.0003 \\
\hline Elective & 19 & 16 & \\
\hline Urgent & 0 & 10 & \\
\hline $\begin{array}{l}\text { Postoperative complications } \\
(n(\%))\end{array}$ & $1(5.3)$ & $13(50.0)$ & 0.0006 \\
\hline $\begin{array}{l}\text { Postoperative hospital } \\
\text { stay (days) }\end{array}$ & 15.3 & 25.5 & 0.004 \\
\hline
\end{tabular}

showed that PNI was the independent risk factor for postoperative delirium, using multivariate analysis in the same population [20]. However, another report could not prove clearly that preoperative PNI (cutoff value 40) was significantly related to PCs, surgical site infections, 3-year relapse-free survival, or 5-year OS in patients older than 80 years [21]. 
Table 4 Univariate and multivariate analyses of postoperative complications

\begin{tabular}{|c|c|c|c|c|c|c|}
\hline & \multicolumn{3}{|l|}{ Univariate } & \multicolumn{3}{|l|}{ Multivariate } \\
\hline & Odds ratio & $95 \% \mathrm{CI}$ & $p$ value & Odds ratio & $95 \% \mathrm{CI}$ & $p$ value \\
\hline Gender (M/F) & 1.21 & $0.34-4.30$ & 0.763 & & & \\
\hline Age $>90$ & 7 & $1.42-34.4$ & 0.013 & 7.11 & $0.98-51.36$ & 0.052 \\
\hline $\mathrm{BMI}<18$ & 2.31 & $0.56-9.48$ & 0.247 & & & \\
\hline $\mathrm{PNI}<45$ & 18 & $2.08-155.37$ & 0.0006 & 18.74 & $1.18-298.04$ & 0.038 \\
\hline $\mathrm{CEA}>5.0$ & 1.04 & $0.28-3.82$ & 0.952 & & & \\
\hline CA19-9> 37 & 0.5 & $0.09-2.77$ & 0.408 & & & \\
\hline Location right & 4.94 & $0.94-25.87$ & 0.036 & 5.03 & $0.656-38.68$ & 0.12 \\
\hline Tumor burden $>15 \mathrm{~mm}^{2}$ & 2.19 & $0.594-8.03$ & 0.232 & & & \\
\hline Stage $3 / 4$ & 0.592 & $0.161-2.18$ & 0.426 & & & \\
\hline
\end{tabular}

The PNI cutoff value in our study was 45 , which is the same value that is associated with safety in gastrointestinal surgery [6]. The current study found that PNI is an independent predictor of PCs in patients aged $\geq 85$ years with CRC, and that low PNI predicted poor prognosis and survival at 3 years after surgery in the same population.

Malnutrition is associated with cancer, and is significantly more common in elderly patients. In elderly patients with some cancers, accurate assessment of preoperative nutritional status is especially important. As PNI is calculated by serum albumin level and total PBL counts, it should mirror both the patient's nutritional status and immune state. Our study associated low PNI with PCs and poor survival in elderly patients with CRC. Improving preoperative nutritional status with nutritional support or rehabilitation should be considered for patients with low PNIs.

This study has some limitations, including its retrospective and single-institution design, small study cohort, and potential selection bias. However, the number of elderly patients aged

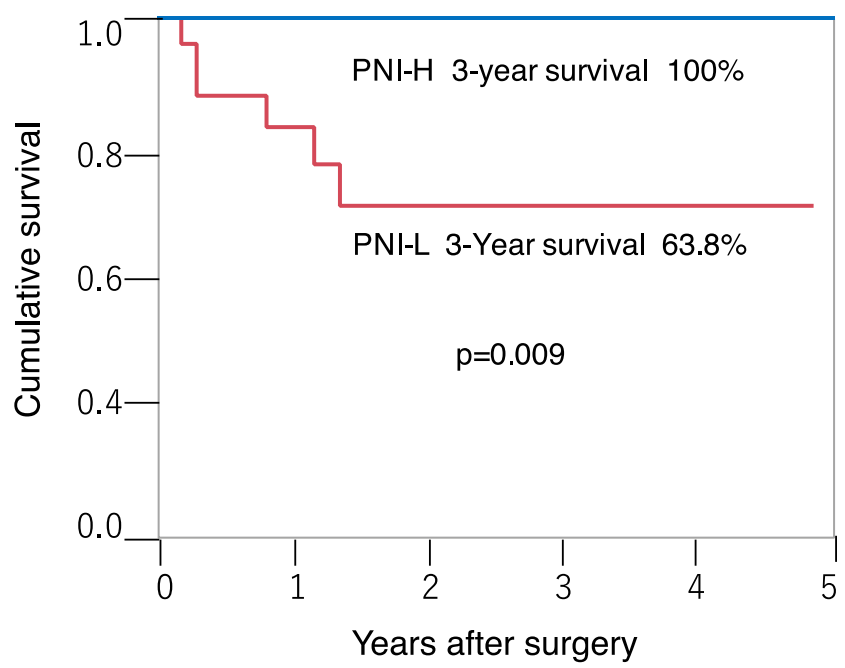

Fig. 1 Overall survival curves based on preoperative prognostic nutritional index $\geq 85$ years with $\mathrm{CRC}$ is not usually very many in a single institute. Moreover, surgical technique was less variable, as performed by one surgeon in a single institute.

To our knowledge, this is the first report that PNI is relevant to PCs and long-term prognosis in patients aged $\geq 85$ years with CRC. However, a prospective large-scale study is needed to clarify the value of PNI for very elderly patients with CRC.

In conclusion, preoperative PNI $<45$ in patients aged $\geq$ 85 years with CRC is both predictive and prognostic for short- and long-term outcomes.

Author Contributions AT conceived the idea, formulated the study design, participated in collecting the data and writing manuscript. YW and SM participated in operative work. HT, TN, YF participated in data analysis and statistical inferences. TU participated in reviewing of the manuscript.

\section{Compliance with Ethical Standards}

The protocol for this research project has been approved by constituted Ethics Committee of the Kawasaki Medical School and Saitama Medical University International Medical Center. It conforms to the provisions of the Declaration of Helsinki in 1995.

Conflict of Interest The authors declare that they have no conflicts of interest.

Open Access This article is licensed under a Creative Commons Attribution 4.0 International License, which permits use, sharing, adaptation, distribution and reproduction in any medium or format, as long as you give appropriate credit to the original author(s) and the source, provide a link to the Creative Commons licence, and indicate if changes were made. The images or other third party material in this article are included in the article's Creative Commons licence, unless indicated otherwise in a credit line to the material. If material is not included in the article's Creative Commons licence and your intended use is not permitted by statutory regulation or exceeds the permitted use, you will need to obtain permission directly from the copyright holder. To view a copy of this licence, visit http://creativecommons.org/licenses/by/4.0/. 


\section{References}

1. Parkin DM, Bray F, Ferlay J, Pisani P (2005) Global cancer statistics, 2002. CA Cancer J Clin 55:74-108

2. Goto S, Hasegawa S, Hida K, Uozumi R, Kanemitsu Y, Watanabe T, Sugihara K, Sakai Y, Study Group for Nomogram of the Japanese Society for Cancer of the Colon and Rectum (2017) Multicenter analysis of impact of anastomotic leakage on longterm oncologic outcomes after curative resection of colon cancer. Surgery $162: 317-324$

3. Ariake K, Ueno T, Takahashi M, Goto S, Sato S, Akada M, Naito H (2014) E-PASS comprehensive risk score is a good predictor of postsurgical mortality from comorbid disease in elderly gastric cancer patients. J Surg Oncol 109:586-592

4. Farid SG, Aldouri A, Morris-Stiff G, Khan AZ, Toogood GJ, Lodge JP, Prasad KR (2010) Correlation between postoperative infective complications and long-term out- comes after hepatic resection for colorectal liver metastasis. Ann Surg 251:91-100

5. Krarup PM, Nordholm-Carstensen A, Jorgensen LN, Harling H (2014) Anastomotic leak increases distant recurrence and longterm mortality after curative resection for colonic cancer: a nationwide cohort study. Ann Surg 259:930-938

6. Onodera T, Goseki N, Kosaki G (1984) Prognostic nutritional index in gastrointestinal surgery of malnourished cancer patients. Nippon Geka Gakkai Zasshi 85:1001-1005 [in Japanese]

7. Nozoe T, Kimura Y, Ishida M, Saeki H, Korenaga D, Sugimachi K (2002) Correlation of pre-operative nutritional condition with postoperative complications in surgical treatment for oesophageal carcinoma. Eur J Surg Oncol 28:396-400

8. Feng JF, Chen QX (2014) Significance of the prognostic nutritional index in patients with esophageal squamous cell carcinoma. Ther Clin Risk Manag 10:1-7

9. Migita K, Takayama T, Saeki K, Matsumoto S, Wakatsuki K, Enomoto K, Tanaka T, Ito M, Kurumatani N, Nakajima Y (2013) The prognostic nutritional index predicts long-term outcomes of gastric cancer patients independent of tumor stage. Ann Surg Oncol 20:2647-2654

10. Kanda M, Fujii T, Kodera Y, Nagai S, Takeda S, Nakao A (2011) Nutritional predictors of postoperative outcome in pancreatic cancer. Br J Surg 98:268-274

11. Mohri Y, Inoue Y, Tanaka K, Hiro J, Uchida K, Kusunoki M (2013) Prognostic nutritional index predicts postoperative outcome in colorectal cancer. World J Surg 37:2688-2692
12. Nozoe T, Kohno M, Iguchi T, Mori E, Maeda T, Matsukuma A, Ezaki T (2012) The prognostic nutritional index can be a prognostic indicator in colorectal carcinoma. Surg Today 42:532-535

13. Dindo D, Demartines N, Clavien PA (2004) Classification of surgical complication: a new proposal with evaluation in a cohort of 6336 patients and results of a survey. Ann Surg 240:205-213

14. Buzby GP, Mullen JL, Matthews DC, Hobbs CL, Rosato EF (1980) Prognostic nutritional index in gastrointestinal surgery. Am J Surg 139:160-167

15. Tokunaga R, Sakamoto Y, Nakagawa S, Miyamoto Y, Yoshida N, Oki E, Watanabe M, Baba H (2015) Prognostic nutritional index predicts severe complications, recurrence, and poor prognosis in patients with colorectal cancer undergoing primary tumor resection. Dis Colon Rectum 58:1048-1057

16. Peng J, Zhang R, Zhao Y, Wu X, Chen G, Wan D, Lu Z, Pan Z (2017) Prognostic value of preoperative prognostic nutritional index and its associations with systemic inflammatory response markers in patients with stage III colon cancer. Chin J Cancer 36:96

17. Zhao Y, Deng Y, Peng J, Sui Q, Lin J, Qiu M, Pan Z (2018) Does the preoperative prognostic nutritional index predict survival in patients with liver metastases from colorectal cancer who underwent curative resection? J Cancer 9:2167-2174

18. Yano Y, Sagawa M, Yokomizo H, Okayama S, Yamada Y, Usui T, Yamaguchi K, Shiozawa S, Yoshimatsu K, Shimakawa T, Katsube T, Kato H, Naritaka Y (2017) Preoperative prognostic nutrition index is a predictive factor of complications in laparoscopic colorectal surgery. Jpn J Cancer Chemother 44:903-905

19. Tei M, Ikeda M, Haraguchi N, Takemasa I, Mizushima T, Ishii H, Yamamoto H, Sekimoto M, Doki Y, Mori M (2009) Postoperative complications in elderly patients with colorectal cancer: comparison of open and laparoscopic surgical procedures. Surg Laparosc Endosc Percutan Tech 19:488-492

20. Tei K, Ikeda M, Haraguchi N, Takemasa I, Mizushima T, Ishii H, Yamamoto H, Sekimoto M, Doki Y, Mori M (2010) Risk factors for postoperative delirium in elderly patients with colorectal cancer. Surg Endosc 24:2135-2139

21. Yoshimatsu K, Yokomizo H, Yano Y, Okayama S, Sakuma A, Satake M, Sagawa M, Matsumoto A, Fujimoto T, Asaka S, Usui T, Yamaguchi K, Shiozawa S, Shimakawa T, Katsube T, Kato H, Naritaka Y (2016) Preoperative prognostic nutritional index in elderly patients over 80 years old who underwent curative resection for colorectal cancer. Jpn J Cancer Chemother 43:1529-1531

Publisher's Note Springer Nature remains neutral with regard to jurisdictional claims in published maps and institutional affiliations. 